\title{
An Assessment of Strategic Management on Supply Chain Management and Logistics - A Path Analysis
}

\author{
Azzam A. Abou-Moghli ${ }^{1}$ \\ ${ }^{1}$ Department of Business Administration, Faculty of Business, Applied Science Private University, Amman, Jordan \\ Correspondence: Azzam A. Abou-Moghli, Department of Business Administration, Faculty of Business, Applied \\ Science Private University, Amman, Jordan
}

Received: July 25, 2018

Accepted: August 27, 2018

Online Published: August 28, 2018

doi:10.5430/jbar.v7n2p29

URL: https://doi.org/10.5430/jbar.v7n2p29

\begin{abstract}
An efficient supply chain management is essential for the survival of organizations in the present competitive business world. Without effectual supply chain management strategies, the performance of organizations deteriorates. The study aims to examine different strategies such as customer orientation, innovating strategy and technological innovation in the financial and non-financial performance of pharmaceutical firms. A path analysis study was conducted in which a questionnaire with regard to strategic management on supply chain and logistics was distributed amongst 10 pharmaceutical companies in Jordan. The results have revealed a positive and significant influence of customer-oriented strategies on the financial performance of companies. In contrast, the results show no significant impact of technological innovation on financial and non-financial performance of the pharmaceutical firms. However, there has been a significant correlation found between innovating strategies and the performance of the organizations. The study has asserted companies to focus and attempt more efforts to enhance their supply chain management strategies to upgrade their performance.
\end{abstract}

Keywords: supply chain management, strategies, customer orientation, innovating strategy, technological innovation

\section{Introduction}

The most dominant objective of any supply chain management is to make certain that a company is delivering the appropriate orders which meet its customer's requirements and to deliver the order at the appropriate time (Hugos, 2018). In addition, when a company is deciding on which supplier to choose, it has to look at the financial aspects of the business and accomplish its objectives by spending as little money as possible (Power, 2005). Subsequently, improving performance and lowering costs will ensure an optimized and enhanced supply chain management and will help an organization survive in this competitive business environment. Supply chain is performed at multiple stages, namely; strategic and operational levels (Wook Kim, 2006). The management of a company makes complex decisions regarding supply chain that are pertinent to the organization (Wisner, Tan \& Leong, 2014).

These supply chain management decisions reflect and are a part of the complete corporate strategy that is followed by an organization (Mangan, Lalwani \& Lalwani, 2016). Supply chain management is indispensable for the survival and growth of a company. There would be no sales without supply chain and the supply of products (Gunasekaran, Patel \& McGaughey, 2004). In addition, the finance department cannot calculate total cost of goods and the profitability without an efficient supply chain department managing the supplier costs. Supply chain management departments are an essential part of every organization in the modern business environment. It is not just the management of the transfer of products to the buyers, but it is also the proper control of time, data and money that are associated with the entire process (Ross, 2013). The field of supply chain management includes negotiations involved in the cost of supply of goods, delivery management of the products and quality audits. Apart from this, supply chain teams also co-ordinate with the quality, engineering and logistic teams (Ellinger, 2000). Amongst the metrics that are assessed, on-time delivery is a common parameter which is monitored.

On-time delivery is not black-and-white and there are many road blocks that are encountered by suppliers. The exact date of delivery can change during the lifetime of an order. There might be re-negotiations and subsequent revised supply dates might be established (Wong, Boon-ITT \& Wong, 2011). During this change, it is essential that the organization and suppliers are aligned and there is a proper co-ordination between the two parties. Along with supply chain management strategies and other strategic decisions made by organizations and manufacturers, the logistics 
function is also critical and essential to the success of the organization. Fulfillment of an order is an essential part of the supply chain function and the management of a company is obligated to take decisions on the logistics linkage too, which is a part of the entire supply chain process (Wook Kim, 2006).

\subsection{Problem Statement}

Logistics is a part of the comprehensive supply chain system and is related to the management of the movement of goods (Christopher, 2016). The management of the supply chain departments of organizations are responsible for managing shipping companies and freight forwarders. In addition, customs brokers and third-party logistics providers have to be dealt with and managed effectively (Bowersox, Closs \& Cooper, 2002). Logistics providers have to be managed in a similar way in which the suppliers are managed. In the same way, costs and contracts can also be negotiated. Warehousing and shipping costs are amongst the largest expenses of supply chain that are incurred by an organization. Therefore, to control costs, it is crucial that logistics providers are monitored and managed appropriately (Waters, 2009). Organizations are usually seeking for efficiency in their supply chains to possess a sustainable development and increasing profit. Thereby, supply chains are directed towards the operational aspects of the organizations as compared to the strategic aspects. Henceforth, it is importance for organizations to seek the strategic aspects of the processes within all departments and organizational members. Subsequently, the role; manager played, is entirely important in decision-making, possessing the power to control resources and enhancing the supply chain performance.

\subsection{Study Significance}

Based on the aforementioned discussion, it is presumed that the primitive and essential objective of any supply chain is to ensure an organization is providing the orders or activities its customer's requirement when they want those orders. Furthermore, it achieve this process by spending as minute as plausible. A supply chain is truly optimized, merely by reducing costs and enhancing performance. In this regard, several questions are raised that surely require attention to be resolved. Firstly, how supply chains aid organizations in interacting within and outside the organization. Secondly, how entire business strategy is framed regarding supply chain strategy. Thirdly, how supply chain functions are collaborated effectively with vendors and customers. Lastly, how organizational functional areas are comprehended through supply chain impacts and relevance. Thereby, the study is intended to examine the influence of strategic management on logistics and supply chain management. Subsequently, it examines the impact of innovating strategy, technological innovation and customer-oriented strategy, on the financial and non-financial performance of pharmaceutical companies.

\subsection{Research Question}

Question 1: What is the impact of strategic management on supply chain management and logistics of pharmaceutical companies?

Question 2: What is the impact of innovating strategy, customer-oriented strategy, and technological innovation on financial and non-financial performance of pharmaceutical companies?

\section{Literature Review}

\subsection{Theoretical Framework}

In turbulent and dynamic business environment, strategy implementation is essential. It is a highly complex and multifaceted organizational issue (Hill, 2017). Superior performance is produced merely for an organization when they are integrated successfully. An appropriate strategy is required for strategic success, but further requires that the strategy is integrated successfully. The failure consequences can be emerged in the form of foregone benefits and formulation costs (Wheelen et al., 2017). Strategy is a primary and major emergent actions taken by managers on behalf of owners, entailing the use of resources for improving the firm's performance in their external environments. Thereby, power and pattern views to strategy creation is the primitive initiative emerged from the most popular psychological aspects of strategic management (Dubey et al., 2017). The initial contribution of industrial economics to strategic management is the examination of strategic groups and structure-conduct-performance example. To obtain competitive advantage and outperforming other organizations in an industry, cost-leadership, focus and differentiation are possible and successful generic strategic approaches. Similarly, agency theory refers to the relationships that emerge when decision-making authority is delegated by an individual to another individual based on a mutual agreement (Lasserre, 2017).

\subsection{Empirical Review}

Chan, Ngai \& Moon (2017) have explored the major antecedents and outcomes of supply chain agility at both the 
operational and strategic levels. In this regard, the study has employed a total of 141 garment manufacturers to analyze the collected data using structural equation modelling. From the findings, it has been clearly investigated that supply chain agility is influenced by manufacturing flexibility and strategic flexibility. Similarly, both strategic and manufacturing flexibilities are mediated positively by supply chain agility with respect to organizational performance.

Tarofder, Azam \& Jalal (2017) have identified the adoption of internet technologies in an organizational supply chain context and investigated the benefits of internet adoption associated with supply chain. A total of 236 respondents from Malaysian industries have been selected to examine the data using structural equation modelling. The findings have portrayed that operational activities are positively influenced by internet technologies as compared to strategic activates.

A study was conducted by Laari et al (2016) to identify the relationship between environmental and financial performance in manufacturing and customer-driven green supply chain management (GSCM) practices. The popular opinion and existing studies show that internal green supply chain management (GSCM) practices influence external activities. However, contrary to this dominating narrative, this study advocates that customer requirements are an important driver in the implementation of internal GSCM practices. The outcome of this study reveals that manufacturers respond to pressures placed by the customers for transferring the burden to supply chain. This is done either by monitoring the suppliers' environmental performance or collaborating with the suppliers. Environmental collaboration with suppliers is a result of environmental monitoring. In addition, type of practices employed directly affect the financial performance of an organization. Collaborative relationship with customers has shown to not only improve the financial performance but also vastly assists in the accomplishment of environmental goals of an organization. The study concluded that companies with strong and stable internal customer driven green supply chain management practices, such as monitoring and collaborating with suppliers; have a higher probability of demonstrating excellent performance.

Another study by Jacobs, Yu \& Chavez, (2016) examined the influence of employee satisfaction and internal communication on supply chain integration. In addition, supply chain integration includes both internal integration and external integration with trading companies. Data was acquired from evolving markets and was related to the emerging market context. Similarly, 214 China based manufacturers contributed in the research study. It was discovered that internal communication within an organization has a significant effect on the satisfaction of the employee. Taking this a step further, it was also discovered that employee satisfaction directly affects the external integration of the organization with its trading partners. The evaluation also revealed that employee satisfaction moderately mediated and facilitated the association between internal integration and internal communication. It was concluded that managers must give added attention to communicating with their employees to enable internal integration and employee satisfaction that would subsequently lead to positive external relationship with trading partners. It was recommended that along with marketing campaigns to win over customers, winning over employees was also equally essential for an organization. Internal integration had a lot of benefits; including more effective, real and active integration with customers. This positive link with the customers would lead to more enhanced market and financial performance.

In a study conducted by Montoya-Torres, Muñoz-Villamizar and Vega-Mejía (2016), the influence of implementing city logistics in urban goods transport of the city of Bogota, Colombia was analyzed and evaluated. City logistics can be defined as the process of total optimization and upgradation of transport activities and logistics of urban areas. In addition, it must earnestly take into account major environmental, economic, social and safety aspects in relation to the transport activities. In this study, collaborative and non-collaborative situations were considered, with regard to the management and urban goods transport planning activities. The findings of the study revealed that when collaborative logistics operations are implemented, there were many quantitative advantages that were observed.

In a study performed by Liu, Prajogo \& Oke (2016), effects of the application of supply chain technologies were analyzed. In addition, the study also investigated levels of the utilization of SCT and its relation to the performance of the organizations that adopt supply chain technologies (SCT). Apart from this, the role of logistics integration and information sharing was also analyzed. The participants of the survey comprised of manufacturing firms in Australia. Integrating new technology into existing operations can help significantly increase customer service and streamline supply chains. It can also reduce costs and increase the financial performance of organizations.

In a study by Flynn et al. (2010), the influence of supply chain integration was evaluated in the smooth functioning of an organization. Supply chain management is closely associated with the harmonious integration of supply chain processes (Gattorna, 2017). The operational and business performance was investigated from a configuration and a 
contingency perspective. The contingency method was applied to decide the influence of various individual supply chain integration dimensions. These included the impact of the supplier, customer and internal integration on the success of the organization.

The study revealed major inconsistencies, one aspect in particular; which was the tendency of organizations and their supply chain departments to focus on supplier and customer amalgamation only. Furthermore, there was an exclusion of the key link of internal organizational assimilation. Apart from this, to achieve smooth movement of products and services, the supply chain management of an organization has to collaborate various organizational processes, money, and decisions to deliver the best value to the customers. It was concluded that both internal and customer integration were more strongly related to improve performance of an organization than supplier integration (Flynn, Huo \& Zhao, 2010).

The aforementioned studies have significantly examined the performance implications of an integrated supply chain strategy using financial performance. Based on the reviews, it is deemed that integrating new technology into existing operations helps significantly in increasing customer service and in streamlining supply chains. It can also reduce costs and increase the financial performance of organizations. The positive link with customers would lead to more enhanced market and financial performance. However, these studies have presented the evidence in developed countries, but there is a lack of evidence related to developing countries. Thereby, this study has formulated the following hypothesis:

$\mathrm{H}_{0}$ : Supply chain management strategy has a negative impact on supply chain capability.

$\mathrm{H}_{1}$ : Supply chain management strategy has a positive impact on supply chain capability.

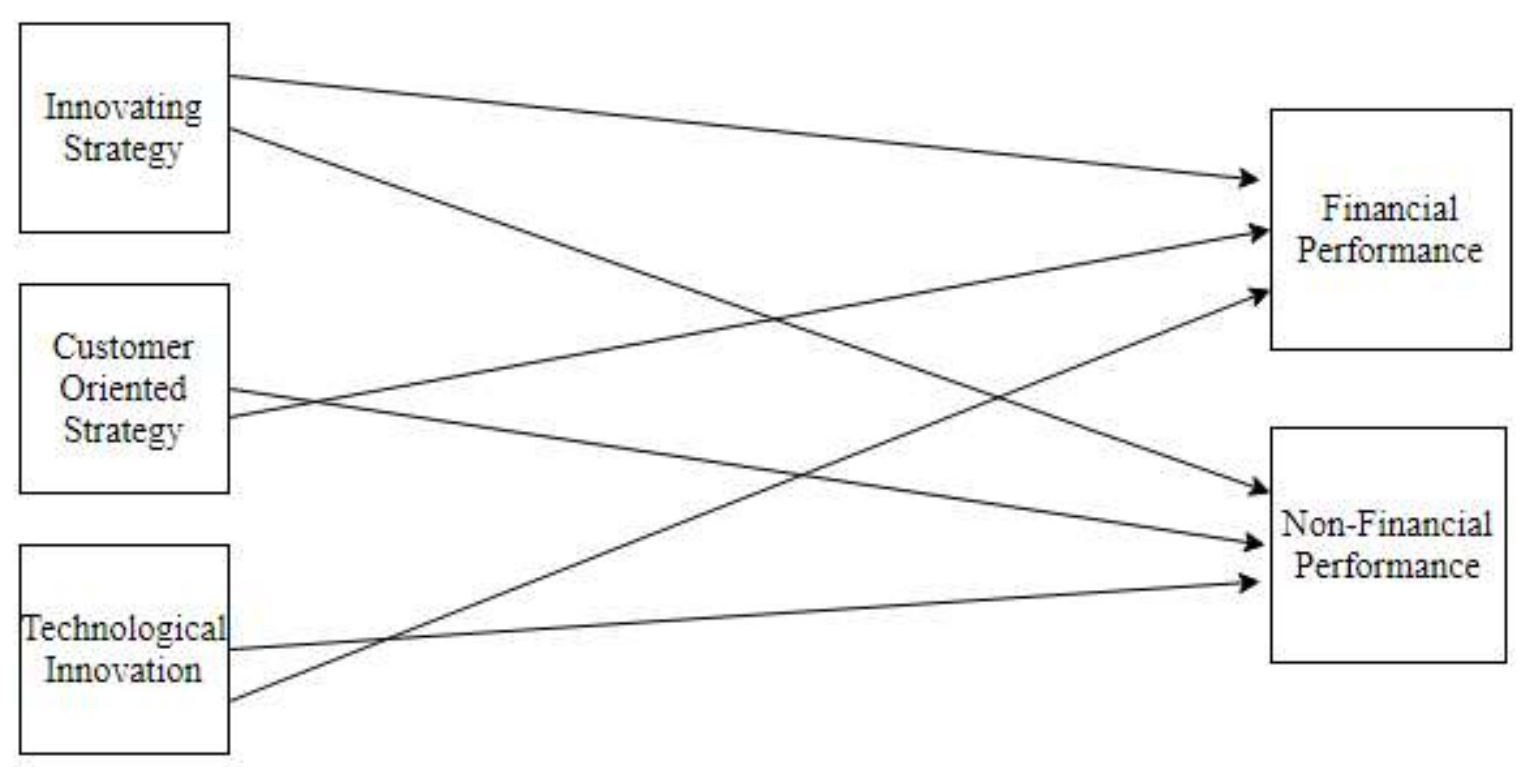

Figure 1. Conceptual Framework

\section{Methodology}

\subsection{Study Design}

A quantitative research design has been opted by the researcher to examine the specific objective of this study. The rationale for adopting this research design was the examination of causal relationship between the study variables. This study scrutinizes the performance implications of an integrated supply chain management strategy using financial performance as a presentation construct.

\subsection{Sampling Technique}

A non-probabilistic sampling technique has been used to recruit potential participants for the study. Based on the adopted sampling technique, the study has opted pharmaceutical companies as study population. A total of 10 pharmaceutical companies have been intended to be included as study population. 


\subsection{Data Collection Procedure}

A comprehensive questionnaire with regard to strategic management on supply chain management and logistics were distributed amongst 10 pharmaceutical companies with wide-ranging markets. Experts, supply chain managers, executives and operation managers were targeted for the study. The questionnaires were distributed among all members of the target population requesting their participation. Out of the total of 177 questionnaires, 125 completed questionnaires were collected. Furthermore, participants were also assured that all responses would remain anonymous.

\subsection{Instrument}

A close-ended questionnaire has been adopted to investigate the data collected. A total of 3 independent (innovating strategy, customer oriented strategy, and technological innovation) and 2 dependent variables (financial performance and non-financial performance) are included in the study. Each factor is based on 3-items. A 5-point Likert scale has been used as a rating scale for the data collection.

\subsection{Data Analysis}

The study also analyses its association with the improvement of the organization and supplier relationship through path analysis. Pharmaceutical companies in Jordan participated in the study. An offer was also made to provide an executive summary to each of the participants. A structural equation modelling (SEM) has been used to analyze the data using SPSS-AMOS. A path analysis was used to estimate parameters of relationship between the relevant construct and the relationship of the organization and the supplier of the company. KMO and Bartlett Test as well as Discriminant Validity has been used for testing sampling adequacy.

\section{Results}

The result of exploratory factor analysis has been presented, which include KMO and Bartlett's test (Table 1). KMO measure of sampling adequacy should be greater than 80 percent and Bartlett's test of Sphericity should be statistically significant at 1 percent confidence interval. However, the study fails to find KMO greater than 80 percent whereas Bartlett's test of sphericity is significant at 1 percent confidence interval.

Table 1. KMO and Bartlett Test

Kaiser-Meyer-Olkin Measure of Sampling Adequacy.

Bartlett's Test of Sphericity

Approx. Chi-Square

1075.830

df

Sig.

Table 2 has presented factor loadings based on exploratory factor analysis, which indicates that it should be greater than 0.60 and total variance should be greater than 60 percent. In the table below, all items have achieved threshold level of 0.60 for loading, whereas, total variance of the model was also 72 percent. Thus, exploratory factor analysis results were accurate and adequate according to the recommended thresholds. 
Table 2. Rotated Component Matrixa

\begin{tabular}{|c|c|c|c|c|c|}
\hline & & & nponent & & \\
\hline & 1 & 2 & 3 & 4 & 5 \\
\hline SM4 & .914 & & & & \\
\hline SM5 & .898 & & & & \\
\hline SM6 & .751 & & & & \\
\hline SM1 & & .876 & & & \\
\hline SM2 & & .861 & & & \\
\hline SM3 & & .806 & & & \\
\hline SCP2 & & & .846 & & \\
\hline SCP3 & & & .781 & & \\
\hline SCP1 & & & .768 & & \\
\hline SCP5 & & & & .925 & \\
\hline SCP6 & & & & .912 & \\
\hline SM8 & & & & & .797 \\
\hline SM7 & & & & & .734 \\
\hline SM10 & & & & & .670 \\
\hline Total & 2.345 & 2.284 & 1.998 & 1.821 & 1.687 \\
\hline$\%$ of Variance & 16.752 & 16.312 & 14.269 & 13.006 & 12.052 \\
\hline Cumulative \% & 16.752 & 33.064 & 47.333 & 60.339 & 72.391 \\
\hline
\end{tabular}

Table 3 has presented construct validity based on factor loading of construct items. The threshold value of factor loading should be 0.60 based on the requirements. Therefore, the model displays construct validity values greater than 0.60 . The study has attained construct validity of all the included variables excluding SCP3, which shows 0.558 . Nonetheless, it is advised that this figure should be taken as round figure so that it can fulfill 0.60 for the construct validity. 
Table 3. Construct Validity

\begin{tabular}{lllcc}
\hline \multicolumn{2}{c}{ Construct Validity } & \\
\hline SM4 & \multicolumn{1}{c}{ Customer } & Esimate & P Value \\
SM5 & $<---$ & Customer & 0.909 & 0.000 \\
SM6 & $<---$ & Customer & 0.911 & 0.000 \\
SM1 & $<---$ & Innovating & 0.569 & 0.000 \\
SM2 & $<---$ & Innovating & 0.753 & 0.000 \\
SM3 & $<---$ & Innovating & 0.892 & 0.000 \\
SCP2 & $<---$ & Financial & 0.716 & 0.000 \\
SCP3 & $<---$ & Financial & 0.891 & 0.000 \\
SCP1 & $<---$ & Financial & 0.558 & 0.000 \\
SCP5 & $<---$ & Non-Financial & 0.669 & 0.000 \\
SCP6 & $<---$ & Non-Financial & 0.985 & 0.000 \\
SM8 & $<---$ & Technological & 0.763 & 0.000 \\
SM7 & $<---$ & Technological & 0.758 & 0.000 \\
SM10 & $<---$ & Technological & 0.482 & 0.000 \\
\hline
\end{tabular}

The fit indices in the below table were all recommended by Hair, Black, Babin, Anderson, and Tatham (2006); Hair et al. (2010) except for AGFI > 0.85 that was suggested by Cole (1987). It has been clearly displayed in the below table that there must be attainment of all the fit indices in both the models. Consequently, due to these model fitness support, CFA and SEM model results have been validated and substantially robust in nature (Table 4).

Table 4. Model Fit Indices

\begin{tabular}{lccc}
\hline & Threshold & CFA & SEM \\
\hline CMIN/DF & $<3.00$ & 1.753 & 1.771 \\
GFI & $>0.80$ & 0.927 & 0.922 \\
AGFI & $>0.80$ & 0.885 & 0.885 \\
CFI & $>0.90$ & 0.950 & 0.946 \\
TLI & $>0.80$ & 0.932 & 0.931 \\
NFI & $>0.80$ & 0.894 & 0.886 \\
RMSEA & $<0.08$ & 0.060 & 0.061 \\
PCLOSE & $>0.10$ & 0.168 & 0.145 \\
\hline
\end{tabular}

The discriminant validity tests are the measurements that are not assumed to be interrelated which are actually unrelated. The discrimination among research variables construct are established on theoretical grounds. In a similar way, it calculates the presence of variance to confirm their separate functionality and individuality among research constructs as supported by the theory (Hair Jr et al., 2016). Table 5 shows all the construct variables based on AVE 
square root and indicated that every specific variable construct has higher values than other constructs. Figure 2 shows the association of construct items with each other.

Table 5. Discriminant Validity

\begin{tabular}{cccccccc}
\hline & CR & AVE & Customer & Innovating & Financial & Non-Financial & Technological \\
\hline Customer & 0.848 & 0.66 & 0.812 & & & & \\
Innovating & 0.832 & 0.626 & 0.056 & 0.791 & & & \\
Financial & 0.756 & 0.518 & $0.173^{*}$ & $0.244^{* *}$ & 0.72 & & \\
Non- Financial & 0.872 & 0.776 & 0.055 & $0.335^{* * *}$ & 0.123 & 0.881 & \\
Technological & 0.609 & 0.352 & 0.146 & $-0.194^{*}$ & $-0.162 \dagger$ & 0.023 & 0.593 \\
\hline
\end{tabular}

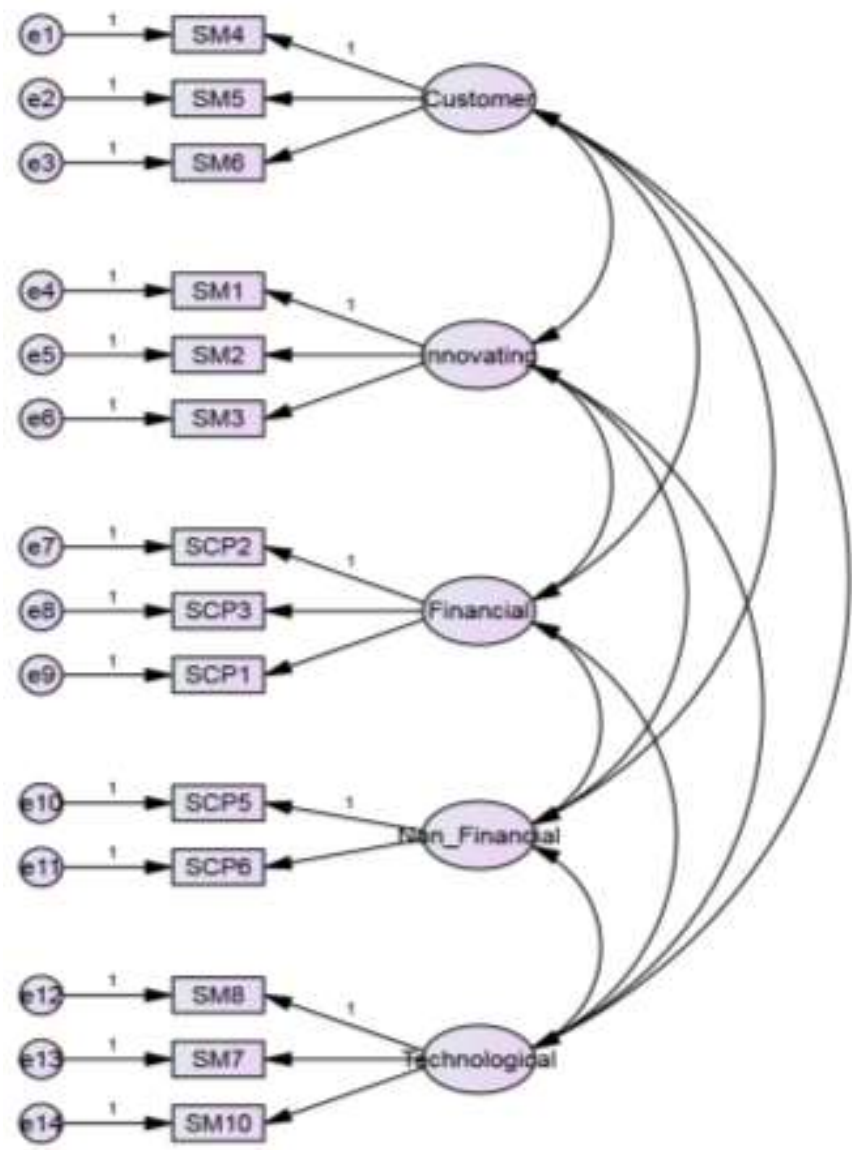

Figure 2. Discriminant Validity

Table 6 has presented regression weights and coefficients through structural equation modeling. The results have revealed a positive and significant impact of customer-oriented strategies on financial performance $(0.096, \mathrm{p}=0.020)$. However, customer-oriented strategies have an insignificant impact on non-financial performance $(0.040, \mathrm{p}=0.650)$. Correspondingly, findings have displayed a positive and significant impact of innovating strategies on both financial performance $(0.121, \mathrm{p}=0.006)$ and non-financial performance $(0.441, \mathrm{p}=0.000)$. In contrast, findings reveal no significant impact of technological innovation on financial $(-0.135,0.119)$ and non-financial performance $(0.147, p=$ 0.410). Figure 3 has presented the relationship of independent variables with dependent variables. 
Table 6. Path Analysis

\begin{tabular}{lllcccc}
\hline \multicolumn{7}{c}{ Path Analysis } \\
\hline Financial & & & Estimate & S.E. & T-Stats & P Value \\
Non-Financial & $<---$ & Customer & 0.096 & 0.041 & 2.321 & 0.020 \\
Financial & $<---$ & Customer & 0.040 & 0.088 & 0.454 & 0.650 \\
Non-Financial & $<---$ & Innovating & 0.121 & 0.044 & 2.738 & 0.006 \\
Financial & $<---$ & Innovating & 0.441 & 0.098 & 4.514 & 0.000 \\
Non-Financial & $<---$ & Technological & -0.135 & 0.087 & -1.560 & 0.119 \\
\hline
\end{tabular}

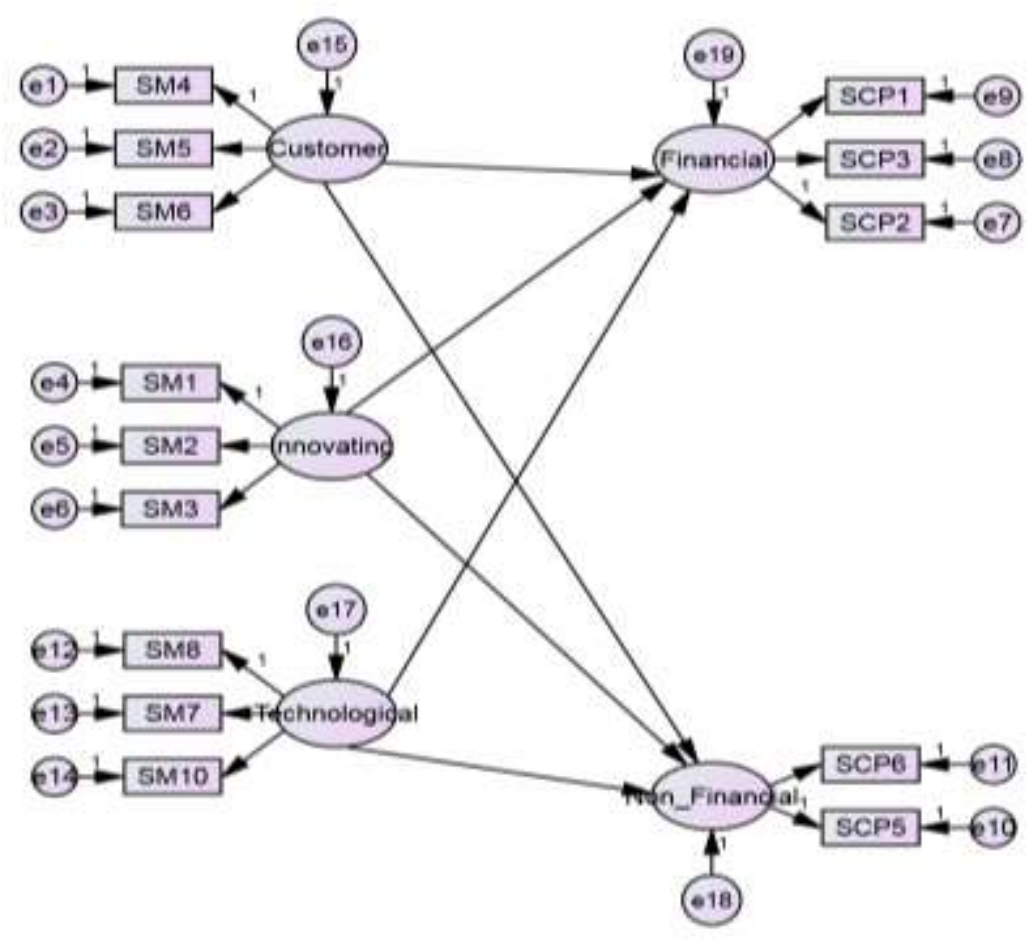

Figure 3. Path Analysis Model

\section{Discussion}

The results are consistent with the study conducted by Frambach, Fiss, \& Ingenbleek (2016). The study revealed that customer orientation is essential for the success of an organization. High-performing firms configure and organize themselves by taking into consideration their customer orientation strategies. Good customer orientation configurations result in efficient marketing and strategic configurations too. These findings are similar to the findings in the present study that reveal that customer orientation has a positively significant effect on the performance of a firm.

The results of the present study contradict the findings in a study conducted by Camisón \& Villar-López (2014), in which the association between technological innovation capacities and organizational innovation was evaluated. The results of the study revealed that organizational innovation encourages the introduction and expansion of technological innovation capacities, consequently resulting in high-level performance of the organization.

Liu, Prajogo \& Oke (2016) have revealed that the optimal utilization of SCT was directly linked with the quality of delivery performance of firms. Consequently, this led to an enhanced level of sharing of information amongst supply chain associates. Similarly, Montoya-Torres, Muñoz-Villamizar and Vega-Mejía (2016) asserted that the results also detected a significant positive environmental impact of the collaborative logistics operations of organizations. 
Consequently, it also led to lower transportation costs and enhanced financial performance of companies implementing optimum collaborative logistics practices. However, the findings of the present study show contradictory results regarding the development of technological innovation on the performance of the company, both financial and non-financial. It reiterates that technological innovation does not significantly improve the financial or the non-financial performance of an organization. However, the present study has revealed that innovative strategies do play a significant role in the performance of an organization.

Supply chain management strategies have a significant impact on supply chain capability of an organization and also influence the overall performance of the company. A positive and significant correlation has been found between customer-oriented strategies on financial performance of a firm. In a similar way, there is a significantly positive relationship between innovating strategies and the financial and non-financial performance of organizations. However, there is an insignificant impact of customer-oriented strategies on non-financial performance of companies. Apart from this, no significant impact was found between technological innovation and financial and non-financial performance of organizations. Therefore, it is recommended that more studies must be conducted on supply chain management strategies and their effect on the various functions of an organization and its overall performance.

\section{Acknowledgments}

The author is very thankful to all the associated personnel in any reference that contributed in/for the purpose of this research.

\section{Conflict of Interest}

The research has no conflict of interest and is not funded through any source.

\section{References}

Bowersox, D. J., Closs, D. J., \& Cooper, M. B. (2002). Supply chain logistics management, 2. New York, NY: McGraw-Hill.

Camisón, C., \& Villar-López, A. (2014). Organizational innovation as an enabler of technological innovation capabilities and firm performance. Journal of business research, 67(1), 2891-2902. https://doi.org/10.1016/j.jbusres.2012.06.004

Chan, A. T., Ngai, E. W., \& Moon, K. K. (2017). The effects of strategic and manufacturing flexibilities and supply chain agility on firm performance in the fashion industry. European Journal of Operational Research, 259(2), 486-499. https://doi.org/10.1016/j.ejor.2016.11.006

Christopher, M. (2016). Logistics \& supply chain management. Pearson UK.

Dubey, R., Gunasekaran, A., Papadopoulos, T., Childe, S. J., Shibin, K. T., \& Wamba, S. F. (2017). Sustainable supply chain management: framework and further research directions. Journal of Cleaner Production, 142, 1119-1130. https://doi.org/10.1016/j.jclepro.2016.03.117

Ellinger, A. E. (2000). Improving marketing/logistics cross-functional collaboration in the supply chain. Industrial marketing management, 29(1), 85-96. https://doi.org/10.1016/S0019-8501(99)00114-5

Flynn, B. B., Huo, B., \& Zhao, X. (2010). The impact of supply chain integration on performance: A contingency and configuration approach. Journal of operations management, 28(1), 58-71. https://doi.org/10.1016/j.jom.2009.06.001

Frambach, R. T., Fiss, P. C., \& Ingenbleek, P. T. (2016). How important is customer orientation for firm performance? A fuzzy set analysis of orientations, strategies, and environments. Journal of Business Research, 69(4), 1428-1436. https://doi.org/10.1016/j.jbusres.2015.10.120

Gattorna, J. (2017). Introduction. In Strategic supply chain alignment (pp. 15-21). Routledge.

Gunasekaran, A., Patel, C., \& McGaughey, R. E. (2004). A framework for supply chain performance measurement. International journal of production economics, 87(3), 333-347. https://doi.org/10.1016/j.ijpe.2003.08.003

Hill, T. (2017). Manufacturing strategy: the strategic management of the manufacturing function. Macmillan International Higher Education.

Hugos, M. H. (2018). Essentials of supply chain management. John Wiley \& Sons. https://doi.org/10.1002/9781119464495

Jacobs, M. A., Yu, W., \& Chavez, R. (2016). The effect of internal communication and employee satisfaction on supply chain integration. International Journal of Production Economics, 171, 60-70. 
https://doi.org/10.1016/j.ijpe.2015.10.015

Laari, S., Töyli, J., Solakivi, T., \& Ojala, L. (2016). Firm performance and customer-driven green supply chain management. Journal of cleaner production, 112, 1960-1970. https://doi.org/10.1016/j.jclepro.2015.06.150

Lasserre, P. (2017). Global strategic management. Macmillan International Higher Education.

Liu, Z., Prajogo, D., \& Oke, A. (2016). Supply chain technologies: Linking adoption, utilization, and performance. Journal of Supply Chain Management, 52(4), 22-41. https://doi.org/10.1111/jscm.12117

Mangan, J., Lalwani, C., \& Lalwani, C. L. (2016). Global logistics and supply chain management. John Wiley \& Sons.

Montoya-Torres, J. R., Muñoz-Villamizar, A., \& Vega-Mejía, C. A. (2016). On the impact of collaborative strategies for goods delivery in city logistics. Production Planning \& Control, 27(6), 443-455. https://doi.org/10.1080/09537287.2016.1147092

Power, D. (2005). Supply chain management integration and implementation: a literature review. Supply chain management: An International journal, 10(4), 252-263. https://doi.org/10.1108/13598540510612721

Ross, D. F. (2013). Competing through supply chain management: creating market-winning strategies through supply chain partnerships. Springer Science \& Business Media.

Tarofder, A. K., Azam, S. F., \& Jalal, A. N. (2017). Operational or strategic benefits: empirical investigation of internet adoption in supply chain management. Management Research Review, 40(1), 28-52. https://doi.org/10.1108/MRR-10-2015-0225

Waters, C. D. J. (2009). Supply chain management: An introduction to logistics, 2. New York: Palgrave Macmillan. https://doi.org/10.1007/978-1-137-26234-9

Wheelen, T. L., Hunger, J. D., Hoffman, A. N., \& Bamford, C. E. (2017). Strategic management and business policy. pearson.

Wisner, J. D., Tan, K. C., \& Leong, G. K. (2014). Principles of supply chain management: A balanced approach. Cengage Learning.

Wong, C. Y., Boon-Itt, S., \& Wong, C. W. (2011). The contingency effects of environmental uncertainty on the relationship between supply chain integration and operational performance. Journal of Operations management, 29(6), 604-615. https://doi.org/10.1016/j.jom.2011.01.003

Wook Kim, S. (2006). Effects of supply chain management practices, integration and competition capability on performance. Supply Chain Management: An International Journal, 11(3), 241-248. https://doi.org/10.1108/13598540610662149 